\title{
A Generalized Approach for Verifying the Emission Benefits of Off-Road Hybrid Mobile Sources
}

\author{
Varalakshmi Jayaram ${ }^{1,2,3} \cdot$ M. Yusuf Khan ${ }^{1,2,4} \cdot$ William A. Welch ${ }^{2} \cdot$ Kent Johnson $^{2}$ • \\ J. Wayne Miller ${ }^{1,2}$ David R. Cocker III ${ }^{1,2}$
}

Received: 1 September 2015 /Revised: 14 December 2015 / Accepted: 16 December 2015/Published online: 27 January 2016

(C) Springer International Publishing Switzerland 2016

\begin{abstract}
More off-road mobile sources are using hybrid technology, and this research outlines a generalized approach for calculating the differences in emissions between conventional and the complex hybrid designs. The basic approach requires simultaneous measurement of activity and emissions for both designs. The case study for this research was a marine vessel, requiring simultaneously measurement of four diesel engines on both vessels and an additional 126 batteries on the hybrid vessel. Analysis of logged data showed both tugs performed the same five activities and the fraction of time at each load for the main propulsion engines was up to $83 \%$ lower than EPA factors. The in-use emissions were measured at operating loads and total emissions from both vessels were calculated using the new weighting factors. Comparative results showed the hybrid tug had significant reductions: $73 \%$ for $\mathrm{PM}_{2.5}, 51 \%$ for $\mathrm{NO}_{\mathrm{x}}$ and $27 \%$ for $\mathrm{CO}_{2}$. Interestingly, most benefits occurred during the transit mode
\end{abstract}

Electronic supplementary material The online version of this article (doi:10.1007/s40825-015-0032-9) contains supplementary material, which is available to authorized users.

David R. Cocker, III

dcocker@engr.ucr.edu

1 Department of Chemical and Environmental Engineering, Bourns College of Engineering, University of California Riverside, Bourns Hall A242, Riverside, CA 92521, USA

2 College of Engineering, Center for Environmental Research \& Technology (CE-CERT), University of California Riverside, 1084 Columbia Ave, Riverside, CA 92507, USA

3 ENVIRON International Corporation, 18100 Von Karman Avenue, Irvine, CA 92628, USA

4 Cummins Inc, 1900 McKinley Ave MC 50010, Columbus, IN 47201, USA and not the standby mode as was the initial hypothesis. During the transit mode, the hybrid energy management system shut down both large propulsion engines and relied on power from batteries and the auxiliary engines now coupled to the propellers. The basic model developed in this research can be applied to other off-road sources and to estimate various scenarios, including retrofits of existing marine vessels or new designs.

Keywords Off-road · In-use · Tugboat · Diesel · Hybrid · Greenhouse Gas

\section{Introduction}

Modern mobile sources are required to simultaneously reduce criteria pollutants, toxics, and greenhouse gas (GHG) emissions, thereby addressing the issues of air quality, energy sustainability, and global climate change. One technical solution to this is the hybrid technology, where two or more energy sources are used for propulsion. The most widespread application of hybrid technology today is for improving fuel economy of on-road passenger vehicles and trucks. Sawyer [1] reported that while on-road criteria pollutant emissions are reduced by up to $99 \%$ with the use of hybrid electric drive technologies, current interest in this technology is primarily driven by concerns about energy security and global climate change. Simultaneously, the allure of fuel savings has led to new products for the off-road market that are promoted with the pitch that fuel savings will offset higher initial capital cost. Such fuel saving products often have limited or no information about actual in-use criteria pollutant emission reductions. 
While hundreds of peer reviewed articles on design, life cycle analysis, strategy, and algorithms for operation of the hybrid technology are available in open literature, there are few articles that quantify the in-use criteria pollutants and greenhouse gases emission reduction benefits of this technology. Regulatory agencies and the Society of Automotive Engineers (SAE) recognized the problems associated with determining compliance with certification standards and establishing a standardized method to quantify fuel and emission benefits of hybrid products. As a result, the California Air Resources Board (CARB) issued a regulatory method [2] dealing with the certification of hybrid and plug-in hybrid electric vehicles; while SAE addressed the issue of measuring fuel economy and emissions of hybrid electric and conventional light- and heavy-duty vehicles in its J1711 [3] and J2711 [4] standards.

Scientists have used simulations and scenario studies to gauge the trade-off of various parameters on the criteria pollutant and GHG emissions. For example, Silva et al. [5] addressed cycles beyond SAE J1711 in a discussion of energy and emissions. Taymaz et al. [6] estimated effects of mixed hybrid systems on fuel consumption and emissions using a road simulation program, while Nüesch et al. [7] reported on the difficulties in design of optimal energy management strategies to balance transient particulate matter (PM) emissions, nitrogen oxide $\left(\mathrm{NO}_{\mathrm{x}}\right)$ emissions, and fuel efficiency for a diesel-electric vehicle. Davies et al. [8] investigated consumer use patterns and operating conditions on energy and emission benefits of plug-in hybrid vehicles. An et al. [9] talked about the critical issues involved in quantifying emissions and fuel consumption for hybrids but few have reported actual in-use data. Fontaras et al. [10] recognized the need for experimental data and reported benefits from two hybrid electric production vehicles against conventional vehicles while following the legislated (New European Driving Cycle) and real-world (Artemis) driving cycles. Takata et al. [11, 12] measured fuel economy and $\mathrm{NO}_{\mathrm{x}}$ emissions for light and medium duty trucks in real traffic conditions with results showing reduced GHG and $\mathrm{NO}_{\mathrm{x}}$ emissions for the hybrid vehicle. Zhang et al. [13] measured on-road $\mathrm{NO}_{\mathrm{x}}$ emissions from several buses using a portable emission measurement system and reported that while hybrid buses reduced GHGs, $\mathrm{NO}_{\mathrm{x}}$ emissions were "unexpectedly higher."

This study not only quantify the benefits pertaining to GHG and criteria pollutants from a complex hybrid system on a marine vessel but also provides a methodology on how to measure and report real world in-use emissions from any off-road hybrid applications. Even though hybrid systems are not significantly present in current offroad fleet, but in near future, it will play a significant role among available technologies in order to reduce GHG emissions which has been the primary focus of policy makers around the world.

\section{Methodology}

Hybrid technologies operate quite differently from conventional technology so this research was launched to provide a standardized procedure to verify the emission benefits of the hybrid units. From a fundamental perspective, emissions from any source are governed by an equation of the form:

$\boldsymbol{E}=\boldsymbol{P} \times \mathrm{LF} \times \boldsymbol{A} \times \mathrm{EF}$

where, $E=$ instantaneous emissions in grams (g),

$P=$ maximum continuous power $(\mathrm{kW})$,

$\mathrm{LF}=$ load factor (percent of total power),

$A=$ activity (h), and

$\mathrm{EF}=$ emission factor $(\mathrm{g} / \mathrm{kWh})$

In principle, expressing Equation 1 over a differential time period and integration over total time would yield total emissions and allow a direct comparison of the emissions from a conventional and hybrid unit. While some engines operate with a throttling feature and are highly transient making the integration difficult, a number of off-road units operate at discreet load points or modes so the total in-use emissions, TE can be expressed as a linear combination of the weighting factors and emissions for each operating mode:

$$
\boldsymbol{T E}=\sum_{i=1}^{n}\left[\boldsymbol{W}_{i} \sum_{j=1}^{m}\left(\boldsymbol{E}_{i j}\right)\right]
$$

where, $n=$ total number of operating modes or discreet load points,

$m=$ total number of engines on the off-road unit,

$W_{i}=$ the weighting factor for $i^{\text {th }}$ operating mode (Equation $3)$, and

$E_{i j}=$ total in-use emissions in $\mathrm{g} \mathrm{h}^{-1}$ from the $j^{\text {th }}$ engine for the $i^{\text {th }}$ operating mode (Equation 4).

The weighting factor for each off-road unit operating mode is calculated as follows:

$W_{i}=\frac{t_{i}}{t_{\text {total }}}$

where, $W_{i}=$ weighting factor for the $i^{t h}$ operating mode,

$t_{i}=$ time spent by the off-road unit in the $i^{\text {th }}$ operating mode, and

$t_{\text {total }}=$ total sample time for the off-road unit.

To determine the total in-use emissions from each engine on the off-road unit the following equation can be used:

$\boldsymbol{E}_{i j}=\sum_{k=1}^{p}\left[\mathrm{WL}_{i j k} \mathrm{EL}_{j k}\right]$

where, $E_{i j}=$ total in-use emissions in $\mathrm{g} \mathrm{h}^{-1}$ from the $j^{\text {th }}$ engine for the $i^{\text {th }}$ operating mode,

$p=$ total number of operating modes for the $j^{\text {th }}$ engine. These modes are based on the $\%$ of maximum engine load: 
off, 0 to $<10 \%, 10 \%$ to $<20 \%, 20 \%$ to $<30 \%$, and so on until $90 \%$ to $<100 \%$ and $100 \%$,

$\mathrm{WL}_{\mathbf{i j k}}=$ the fraction of time spent by the $j^{\text {th }}$ engine at its $k^{\text {th }}$ operating mode during the $i^{\text {th }}$ operating mode (obtained from the engine histogram), and

$\mathrm{EL}_{j \boldsymbol{k}}=$ emissions in $\mathrm{g} \mathrm{h}^{-1}$ for the $j^{\text {th }}$ engine at its $k^{\text {th }}$ operating mode (obtained from the engine's emission profile).

Note that the state of charge (SOC) of the batteries at the end of each sample period, used for developing engine histograms of the off-road unit, should return to within $1 \%$ of the original state of charge at commencement of the sample period based on guidelines provided in the hybrid electric vehicle testing protocols from the SAE [3, 4] and CARB [2]. This was ensured by manually dividing the total logged data into smaller time periods with total change of SOC within $1 \%$. This procedure will eliminate biases in emissions caused by the use of the off-road unit engines for charging batteries.

Taken in total, the emission benefits of a hybrid off-road unit is calculated as follows

Emission Reduction $\%=\frac{\mathrm{TE}_{\mathrm{CT}}-\mathrm{TE}_{\mathrm{HT}}}{\mathrm{TE}_{\mathrm{CT}}} \times 100$

where, $\mathrm{TE}_{\mathrm{CT}}=$ total in-use emissions for the conventional offroad unit in $\mathrm{g} \mathrm{h}^{-1}$, and

$\mathrm{TE}_{\mathrm{HT}}=$ total in-use emissions for the hybrid off-road unit in $\mathrm{g} \mathrm{h}^{-1}$.

\section{Experimental Method}

The methodology described above was used to determine the emission benefits from the world's first hybrid tug. Engine loads and activity during real-time operation were measured and recorded for about 1 month on two tugs (hybrid and conventional) using a special data logger developed for this project. Next, the emissions were determined for each operating mode observed in the data logging. In the final analysis step, activity and emission data were combined to determine the total emissions for the hybrid and conventional tugs.

\subsection{Test Units}

Two harbor tugs were chosen, one conventional and the other hybrid, both operating in the San Pedro Bay, each with two main engines (MEs) and two auxiliary engines/generators (AEs) (Table 1), all meeting EPA Tier 2 standards. The conventional tug (CT) had Caterpillar MEs rated at $1902 \mathrm{~kW}$ directly connected to the propeller for propulsion and AEs rated at $195 \mathrm{~kW}$ for the winch motor and hoteling requirements.

The hybrid tug (HT) had Cummins MEs rated at $1342 \mathrm{~kW}$ and AEs rated at $317 \mathrm{~kW}$. A significant design feature was the inclusion of a motor-generator unit mounted on the shaft of each ME to the propeller. These units allowed power from the batteries or AEs to propel the tug as well as capture regenerative power from freewheeling propellers. With the clutch engaged, the motor-generator was able to produce from the shaft using the MEs or freewheeling propeller. With the clutch open, the motor-generator used electrical power from the batteries and AEs to drive the shaft for propelling the tugboat. As a result of the motor-generator coupler, the power ratings of MEs on the HTs were $29 \%$ lower and the AEs were $63 \%$ higher than those on the CT. A schematic of the HT drive train is provided in the supporting information (Figure SI-1). Two soft-gel lead acid battery arrays, each with sixty-three batteries and a total energy capacity of $170.1 \mathrm{~kW}$-h at full charge completed the design of the HT. Batteries during this research were primarily charged by the AEs (and not MEs); however, plans were in place to use shore power for further emission benefits. The key operating feature of the HT was the energy management algorithm that determined which power sources to use during tug operation. The captain on the HT used a switch in the wheelhouse to indicate the current tug operating mode which subsequently allowed the energy management system to engage appropriate power sources.

Table 1 Test engine specifications

\begin{tabular}{|c|c|c|c|c|}
\hline \multirow[t]{2}{*}{ Engine parameters } & \multicolumn{2}{|c|}{ Conventional tug } & \multicolumn{2}{|l|}{ Hybrid tug } \\
\hline & Main engine & Auxiliary engine & Main engine & Auxiliary engine \\
\hline Manufacturer /model & CAT $3512 \mathrm{C}$ & John Deere 6081 AFM75 & Cummins QSK50 M & Cummins QSM11 \\
\hline Manufacture year & 2008 & 2008 & 2007 & 2007 \\
\hline Technology & 4-stroke diesel & 4-stroke diesel & 4-stroke diesel & 4-stroke diesel \\
\hline Maximum power rating $(\mathrm{kW})$ & 1902 & 195 & 1342 & 317 \\
\hline Rated speed (rpm) & 1800 & 1800 & 1800 & 1800 \\
\hline \# of cylinders & 12 & 6 & 16 & 6 \\
\hline Total displacement (liters) & 58.6 & 8.1 & 50 & 10.8 \\
\hline EPA certification level & Tier 2 & Tier 2 & Tier 2 & Tier 2 \\
\hline
\end{tabular}


Fig. 1 Weighting factors for tug operating modes

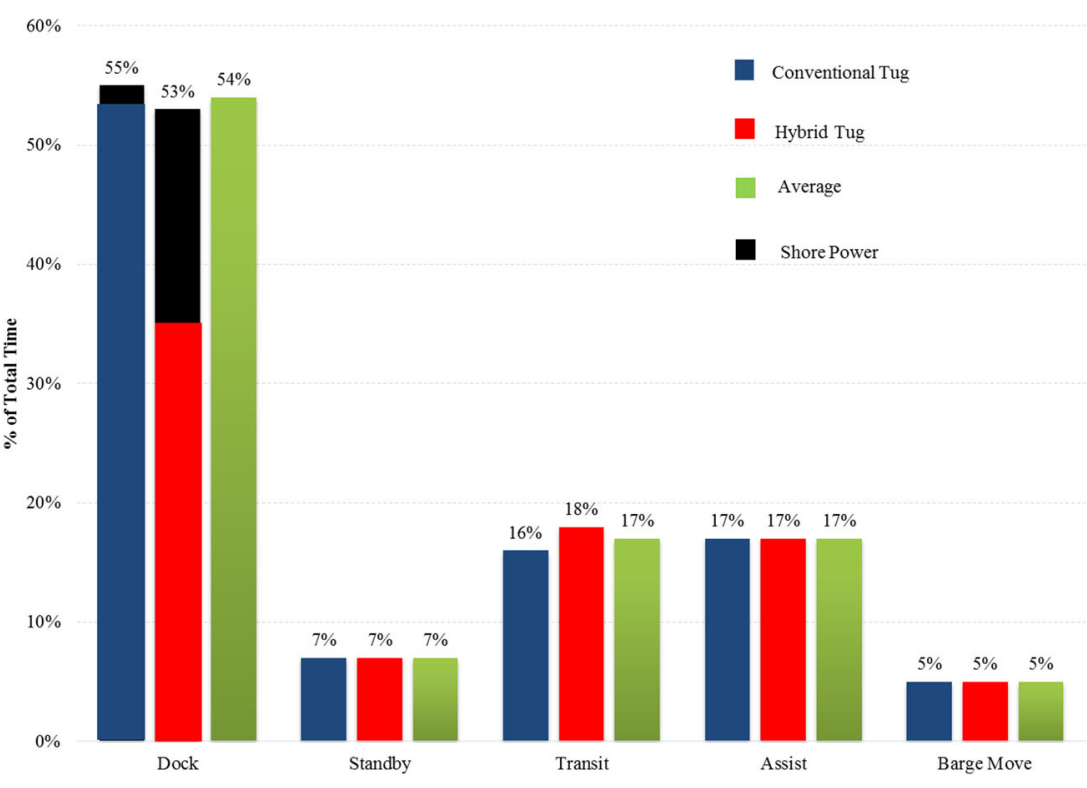

\subsection{Activity Based Measurements}

As explained in the methodology, the first step involved about 1 month of data logging on each tug to establish (1) operating modes, (2) weighting factors, and (3) engine histograms. The novel data logging system designed for this research enabled a $1-\mathrm{Hz}$ collection of engine speed, load, and fuel flow from all four engines using the link with the electronic control modules (ECMs); position and speed data from a GPS and battery state of charge for the HT. Details of the data logging procedure (data logger components, logged parameters, test matrices, and data logging setup) and methods used to develop operating mode weighting factors and engine histograms are provided in supporting information (SI). ECM load readings for speeds $<1200 \mathrm{rpm}$ on the main engine of the CT required a $\mathrm{CO}_{2}$-based correction (SI). Activity data was collected for $\sim 34$ days on the $\mathrm{CT}$ and $\sim 48$ days on the HT.

\subsection{Emission Based Measurements}

The second step involved measurement of the in-use emissions for one $\mathrm{ME}$ and one $\mathrm{AE}$ on each tug and was carried out in two phases. In Phase 1, the emissions were measured while the engine operated at loads specified in ISO 8178-4 and used for certification. This phase was to establish that the engines met the EPA Tier 2 standard. Phase 2 emission measurements were at loads observed in the data logging but not in the ISO certification matrix. With the second set of measurements, emissions/load data were available across the entire in-use operating range. Ultra-low CARB diesel was used during the testing and emissions were measured following ISO $8178-1$ protocols. Test matrices, engine specifications, select fuel properties, test setup schematics, gaseous, and particulate matter $\left(\mathrm{PM}_{2.5}\right)$ measurement methods and calculations of exhaust flow rates and emission factors are provided in SI.
Fig. 2 Conventional tug main engines histogram during transit




Fig. 3 Conventional tug engine histogram during ship assist

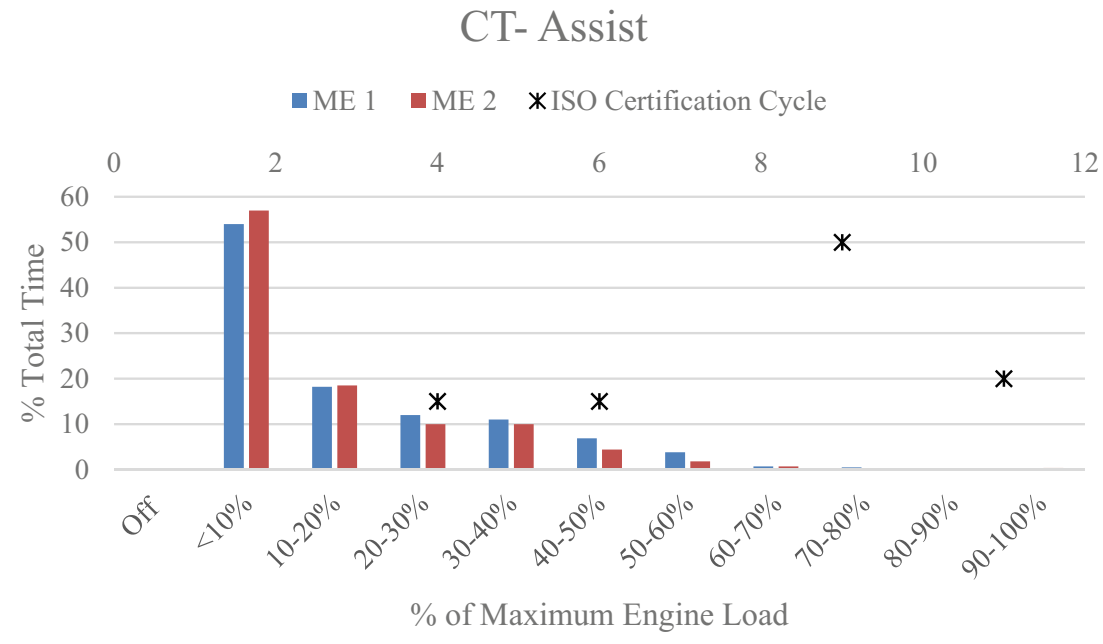

\section{Results and Discussion}

\subsection{Tug operating modes and weighting factors}

Analysis of the captain's log and recorded data from the digital loggers showed there were five discreet and similar modes of operation for both the CT and the HT. These modes were:

\subsubsection{Shore Power}

Tug was plugged into shore power for utilities, no engines operate.

\subsubsection{Dock}

Tug was at dock with one AE powering the lights and air conditioning. The HT switches between the AE and batteries during this mode. The state of charge of the battery arrays were maintained above $60 \%$ with the AE.

\subsubsection{Standby}

Tug was idling in the water waiting for a call to start or transit to a job. The CT operated two MEs and one AE during idling while the HT switches between the batteries and one auxiliary engine.

\subsubsection{Transit}

This mode referred to the movement of the tug between jobs and to and from different docks. The CT boat operated two MEs and one AE. The HT uses batteries and one auxiliary engine for slow speeds ( $<6.0$ knots) and two auxiliary engines for higher speeds.

\subsubsection{Ship Assist and Barge Moves}

Tugs typically perform two kinds of jobs in the ports: (1) assisting ships from berth to sea and vice versa and (2) moving barges from one location to another. The CT operates two MEs and one AE while the HT operates all four engines during a job and uses the energy manger system to optimize the energy use.

Results showed the tugs spent an average $\sim 54 \%$ of its total operating time at dock including shore power; $7 \%$ in standby; $\sim 17 \%$ in transit; $\sim 17 \%$ in ship assist, and $\sim 5 \%$ making barge moves (Fig. 1). The individual weighting factors for CT and HT were nearly identical for all operating modes. However, the HT spent a third of its time at dock plugged into shore power while the CT hardly ( $\sim 1 \%$ of total time) plugged in. Moreover, weekly variations in the weighting factors were small and provided in Table SI-6 and SI-7.

\subsection{Engine Histograms}

\subsubsection{Conventional Tug}

For all operating modes, except shore power, the CT had one AE operating at $10 \%-12 \%$ of its rated power and the other $\mathrm{AE}$ was off all the time. The MEs on the CT were off when the tug was at dock and at $\sim 5 \%$ of their maximum rated power when the CT was at standby. Figures 2 and 3 show engine histograms of both MEs for transit and assist modes, respectively. These MEs were found to operate predominately at loads $<50 \%$ of maximum power rating. The average load required on the CT was found to be $718 \mathrm{~kW}$ for transit, $608 \mathrm{~kW}$ for ship assist and
Table 2 Average load requirements for each operating mode in conventional and hybrid tug boat

\begin{tabular}{lll}
\hline Operating modes & \multicolumn{2}{l}{ Average load (kW) } \\
\cline { 2 - 3 } & CT & HT \\
\hline Dock & 22 & 29 \\
Standby & 184 & 74 \\
Transit & 718 & 278 \\
Assist & 608 & 508 \\
Barge Move & 754 & 507 \\
\hline
\end{tabular}


Fig. 4 Auxiliary engine histogram for hybrid tugboat during transit

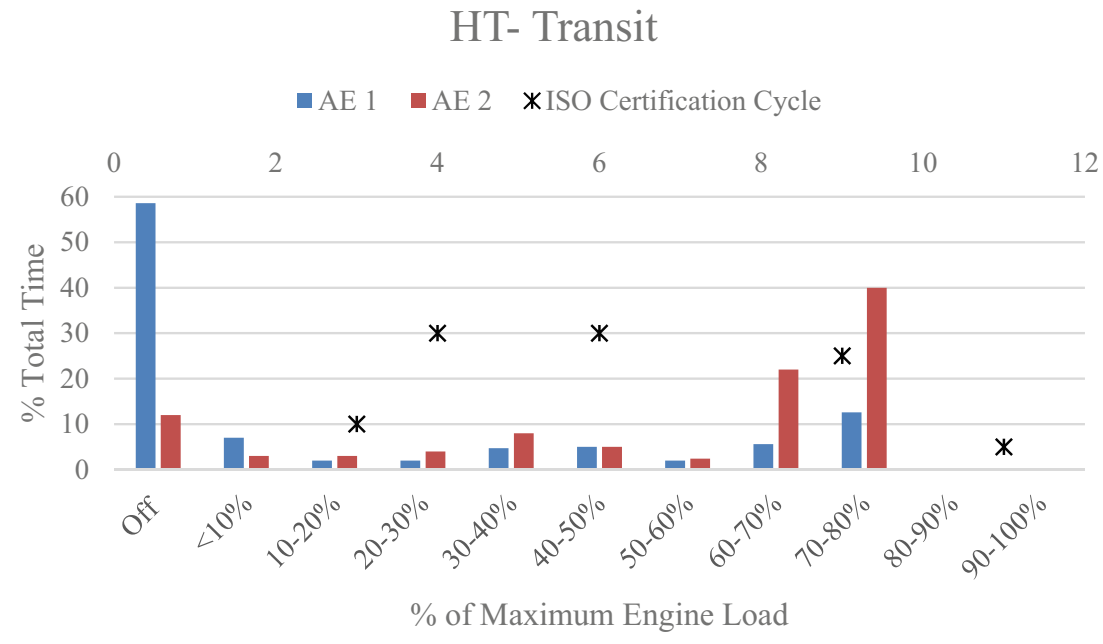

$754 \mathrm{~kW}$ for barge move (Table 2). The engine histogram during barge move revealed that the both ME spent more time in 20$40 \%$ of maximum engine load in comparison to ship assist. Typically two to three tugs help maneuver a ship during a ship assist, along with the ship's ME. Barges with no propulsion engines are moved by a single tug leading to the larger average load requirement for a barge move than a ship assist.

\subsubsection{Hybrid Tug (HT)}

The HT required a load of $29 \mathrm{~kW}$ for hoteling power at dock. When not plugged into shore power, this tug was powered by batteries ( $78 \%$ of the time at dock) or one AE ( $22 \%$ of time at dock). During standby mode the HT was powered by only batteries $\sim 30 \%$ of the time, one AE $\sim 53 \%$ of the time, and more than one $\mathrm{AE} \sim 17 \%$ of time. Figures $4,5,6$, and 7 show the engine histograms for all four HT engines during transit and ship assist. The HT used two AEs when transiting at speeds $>6.0$ knots for $\sim 30 \%$ of time. The MEs generally operated only for a ship assist or barge move. However, the MEs were sometimes on during standby and transit modes; e.g., the five minute
ME cool down period after a job or for safety concerns such as dense fog when the captain chose to keep all engines on. The average load required for the HT to transit $(\sim 278 \mathrm{~kW})$ was $61 \%$ lower than that required by the CT because the HT's energy management system directs use of the AE and battery power for propulsion during transit whereas CT was using MEs. The average load required for ship assist and barge moves for the HT were $16 \%$ and $33 \%$ lower than the CT due to significant use of auxiliary engines on the HT.

\subsection{In-Use versus ISO Load Factors}

Overall, the data showed the average loads on the ME and AE of the CT are $16 \%$ and $12 \%$ of the maximum rated power, respectively. For the HT average loads of ME and AE were $12 \%$ and $34 \%$ of the rated power, respectively. These values were well below the load factors of the standard ISO duty cycles, which better represent the propeller curve for a ship operating in the open sea rather than a harbor tug (Figs. 2, 3, 4, 5, 6, and 7). Use of the ISO load factors instead of the measured in-use load factors for emission inventory calculations could result in overestimation
Fig. 5 Main engine histogram for hybrid tugboat during transit

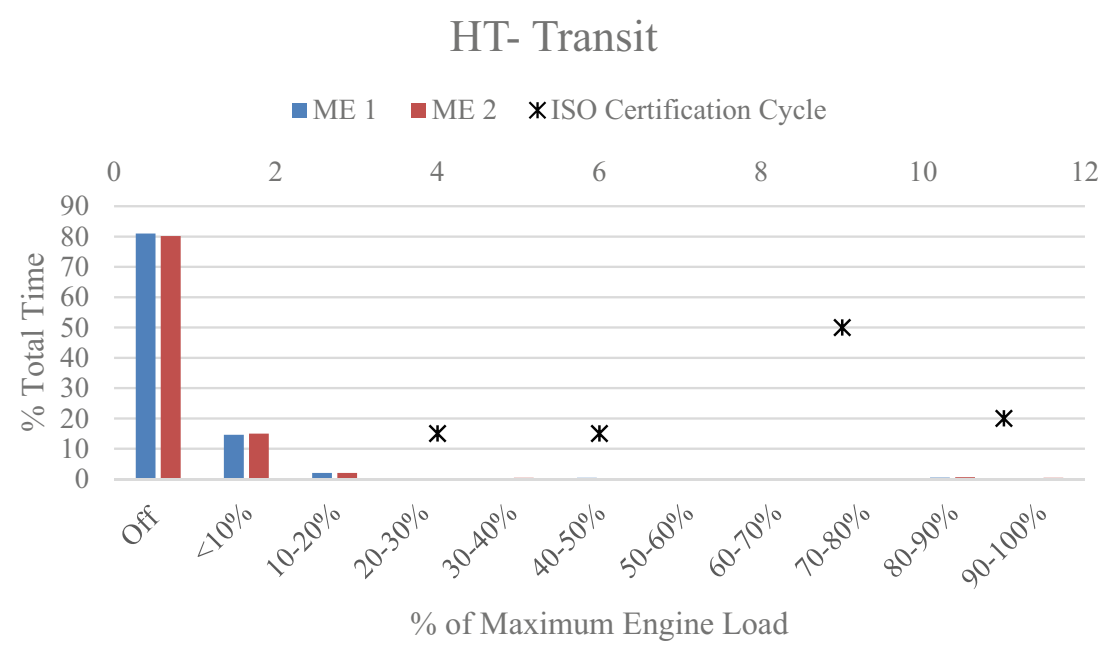


Fig. 6 Auxiliary engine histogram for hybrid tugboat during ship assist

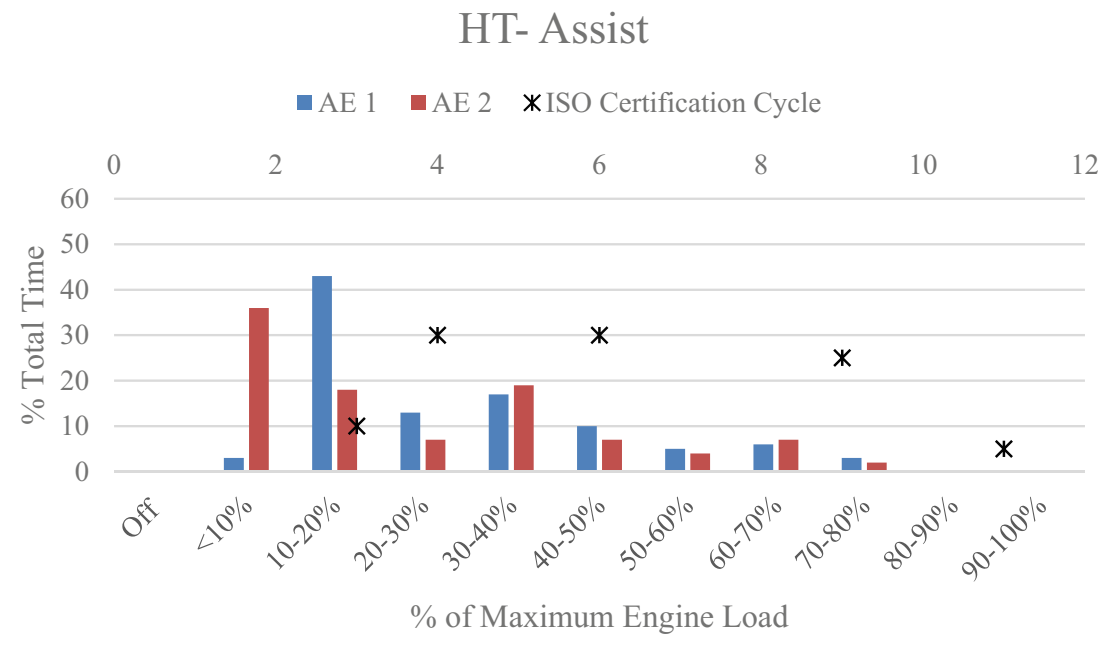

of the $\mathrm{CO}_{2}, \mathrm{NO}_{\mathrm{x}}$, and $\mathrm{PM}_{2.5}$ emissions from these engines by $63 \%$ to $77 \%$. The average load factors of the HT indicate that these engines are still operating in their inefficient zone suggesting the need for a larger energy storage system and possibly smaller MEs in the next generation of hybrid tugs, assuming the tug could still generate the design pulling power.

\subsection{Emission Data}

Figure 8 shows the in-use overall weighted average emission factors of $\mathrm{CO}_{2}, \mathrm{NO}_{\mathrm{x}}$ and total, and speciated $\mathrm{PM}_{2.5}$ mass measured during Phase 1 of emissions testing. Modal data are provided in Table SI-8 along with the manufacturer's published emission factors for each test engine family. Duplicate/triplicate measurements were made at ISO test modes and the standard deviation for gases was $<5 \%$ and for $\mathrm{PM}_{2.5}$ mass emissions was $<11 \%$.

The overall weighted average $\mathrm{NO}_{\mathrm{x}}$ emission factors for these engines ranged from 7.1 to $7.8 \mathrm{~g} \mathrm{~kW}^{-1} \mathrm{~h}^{-1}$. Compared with the Tier 2 Standard, the CAT 3512C was slightly less and the others slightly above; however, all would be within the EPA limits if the allowance for in-use measurements was applied (Fig. 8). The overall weighted average $\mathrm{PM}_{2.5}$ mass emission factors, for three out of the four engines, were well below the EPA Tier 2 standard of $0.20 \mathrm{~g} \mathrm{~kW}^{-1} \mathrm{~h}^{-1}$ (Fig. 8). Measured emissions factors for the CAT $3512 \mathrm{C}$ engine were comparable to the manufacturer's published values. For the Cummins engines, measured $\mathrm{NO}_{\mathrm{x}}$ emission factors were $\sim 19 \%$ greater and $\mathrm{PM}_{2.5}$ emission factors were $41 \%$ to $57 \%$ less than the manufacturer's numbers.

Figure 9 shows the emission profiles of all four engines across several load points obtained during Phase 2 of emission testing. Figure $9 \mathrm{~A}$ and $\mathrm{B}$ shows emissions of $\mathrm{NO}_{\mathrm{x}}, \mathrm{CO}_{2}$, and $\mathrm{PM}_{2.5}$ in $\mathrm{g} / \mathrm{h}$ over the wide range of engine load for $\mathrm{CT}$ auxiliary and main engine. Similarly, emissions were measured for HT auxiliary and main engines. These emissions were combined with engine histogram data to determine the overall in-use emissions as shown in next section. No filter measurements were made for $\mathrm{PM}_{2.5}$ emissions during this phase. Instead, TSI's DustTrak was used for $\mathrm{PM}_{2.5}$ measurements to aid extrapolation of $\mathrm{PM}_{2.5}$ filter measurements between the steady state loads measured during Phase 1 . Since the DustTrak is not a reference method, results from Phase 2 were
Fig. 7 Main engine histogram for hybrid tugboat during ship assist

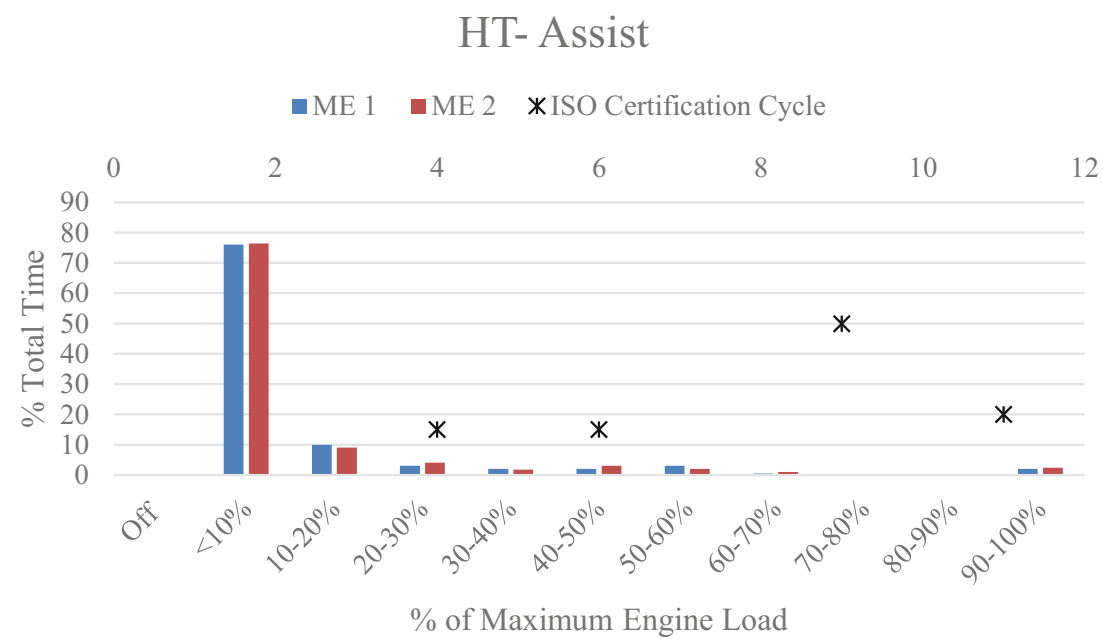


Fig. 8 In-use weighted average emissions factors based on ISO certification cycle

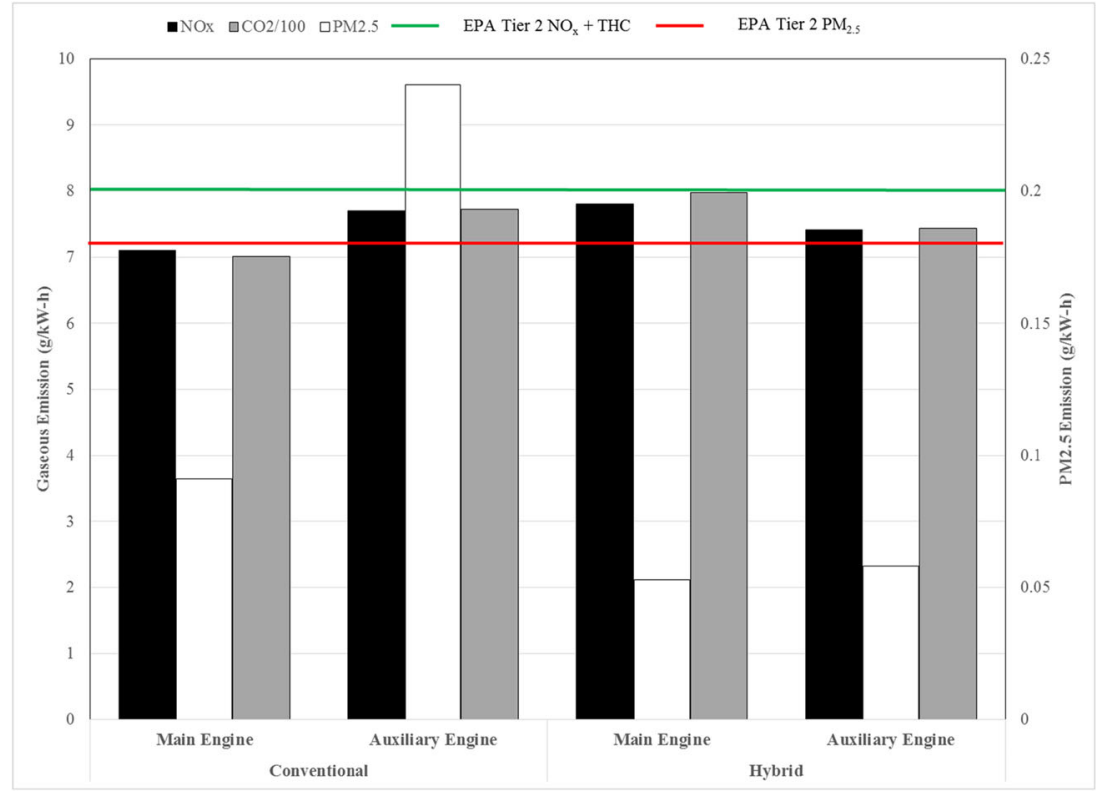

used only to aid in determining PM concentration versus load trends (Figures S1-S10).

\subsection{Overall In-Use Emissions}

The engine activity histograms were coupled with the emission profiles (Equation 4) to determine the total emissions of $\mathrm{PM}_{2.5}, \mathrm{NO}_{\mathrm{x}}$, and $\mathrm{CO}_{2}$ emissions for each tug at every tug operating mode. The emissions for the shore power mode for each tug were calculated as the product of its load requirement at dock and the emission factors of a conventional natural gas fired steam plants with selective catalytic reduction (SCR) for $\mathrm{NO}_{x}$ control and no $\mathrm{CO}$ catalyst (Table SI-9). The total in-use emissions from each tug was calculated using Equation 2 and the individual tug operating mode weighting factors are shown in Table 3.

Using Equation 5, the HT showed overall emission reductions of $73 \% \mathrm{PM}_{2.5}, 51 \% \mathrm{NO}_{\mathrm{x}}$ and $27 \%, \mathrm{CO}_{2}$. The $\mathrm{CO}_{2}$
Fig. 9 Emissions profile of $(A)$ auxiliary engine on conventional tug $(B)$ main engine on conventional tug $(C)$ auxiliary engine on hybrid tug $(D)$ main engine on hybrid tug
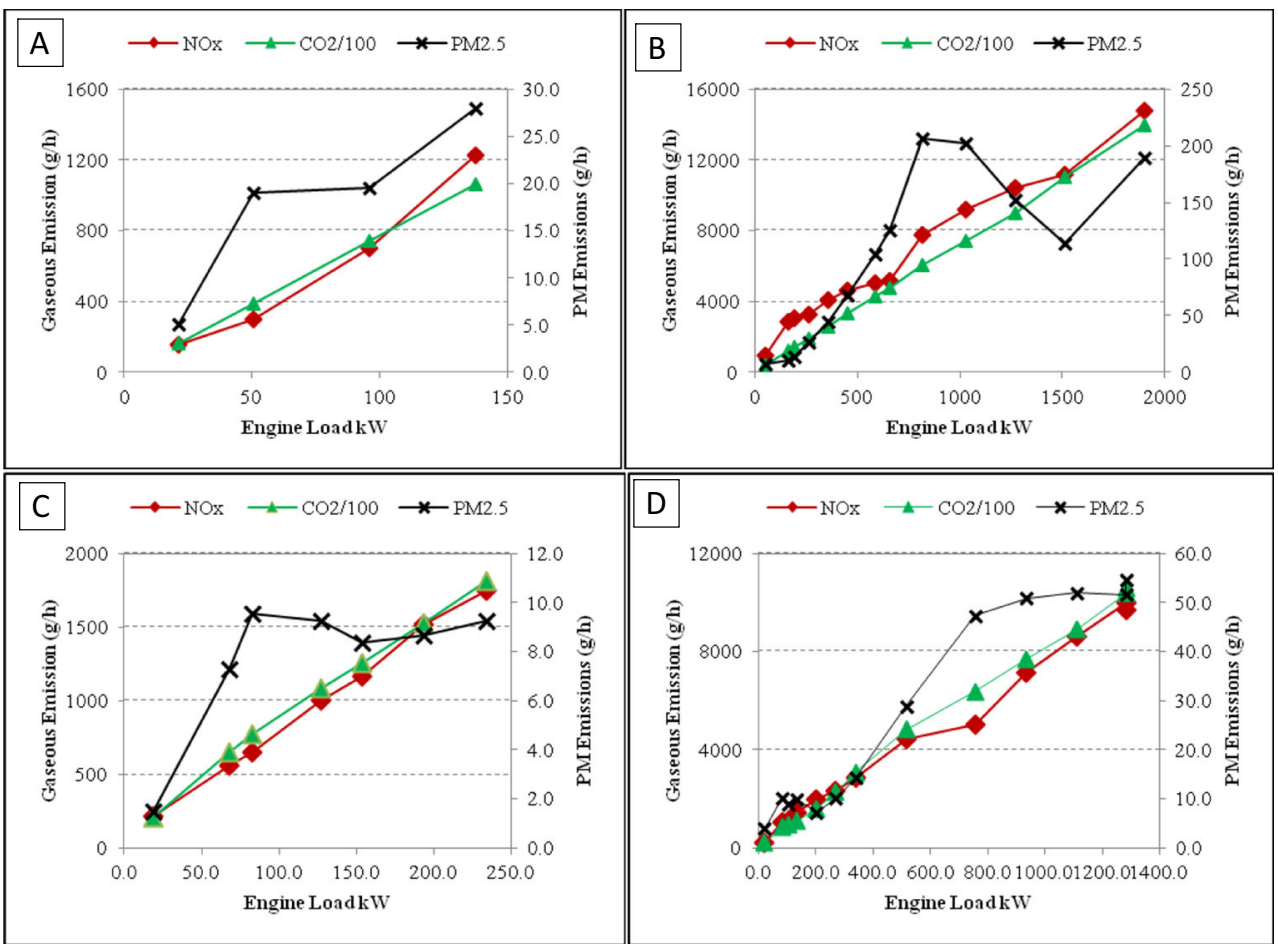
Table 3 Modal and overall emission reductions with hybrid technology

\begin{tabular}{|c|c|c|c|c|c|c|c|c|}
\hline \multirow[t]{2}{*}{ Operating modes } & \multicolumn{2}{|c|}{$\begin{array}{l}\text { Operating modes weighting } \\
\text { factors }\end{array}$} & \multicolumn{2}{|c|}{$\mathrm{PM}_{2.5}(\mathrm{~g} / \mathrm{h})$} & \multicolumn{2}{|c|}{$\mathrm{NO}_{\mathrm{x}}(\mathrm{g} / \mathrm{h})$} & \multicolumn{2}{|c|}{$\mathrm{CO}_{2}(\mathrm{~kg} / \mathrm{h})$} \\
\hline & $\mathrm{CT}$ & HT & $\mathrm{CT}$ & HT & $\mathrm{CT}$ & HT & $\mathrm{CT}$ & HT \\
\hline Shore power & 0.00 & 0.18 & 0.0009 & 0.0012 & 0.011 & 0.0015 & 0.014 & 0.018 \\
\hline Dock & 0.54 & 0.35 & 5.1 & 1.1 & 156 & 89 & 16 & 10 \\
\hline Standby & 0.07 & 0.07 & 26.6 & 7.3 & 3757 & 677 & 176 & 68 \\
\hline Transit & 0.17 & 0.18 & 114.8 & 15.5 & 7633 & 2371 & 530 & 240 \\
\hline Barge Move & 0.05 & 0.05 & 133.1 & 36.4 & 7666 & 4659 & 555 & 457 \\
\hline Ship Assist & 0.17 & 0.17 & 82.5 & 38.3 & 6452 & 4541 & 424 & 450 \\
\hline \multicolumn{3}{|c|}{ Overall emissions using Wt. Factors } & 44.1 & 12.1 & 3088 & 1528 & 208 & 153 \\
\hline \multicolumn{3}{|c|}{$\%$ reduction from conventional tug } & & $73 \%$ & & $51 \%$ & & $27 \%$ \\
\hline
\end{tabular}

reductions were in good agreement with the fuel savings of 25-28\% measured by the tug owner over an eight month period. While idling was initially hypothesized to show the greatest benefits for the HT, the data revealed that the transit mode was the largest contributor to the overall emission reductions, showing $\sim 50 \%$ for $\mathrm{PM}_{2.5}, \sim 53 \%$ for $\mathrm{NO}_{\mathrm{x}}, \sim 78 \%$ for $\mathrm{CO}_{2}$. These reductions occurred because the $\mathrm{HT}$ was powered during transit by one or two AEs and batteries while the $\mathrm{CT}$ used one $\mathrm{AE}$ and two MEs, the later operating inefficiently at $<10 \%$ power.

\subsection{Scenario Planning}

Since the engines in the CT and HT were from different engine manufacturers and had different power ratings, a couple of design/retrofit scenarios were modeled. Scenarios presented here are limited to engines tested in this study and for tug boat application however they provide a good example of predetermining emissions benefits prior to retrofitting of any mobile source if activity and emissions profile of engine (s) are available.

\subsubsection{Scenario 1}

This scenario assumed both the CT and HT were designed with the larger engines: CAT 3512C MEs and Cummins QSK-11 M AEs. In the retrofit option, one considers changing the two AEs on an existing CT. The calculated emission benefits of the HT based on average weighting factors determined in this research was: $57 \%$ for $\mathrm{PM}_{2.5}, 38 \%$ for $\mathrm{NO}_{\mathrm{x}}$ and $31 \%$ for $\mathrm{CO}_{2}$. The $\mathrm{NO}_{\mathrm{x}}$ and $\mathrm{PM}_{2.5}$ benefits decreased while that of $\mathrm{CO}_{2}$ increased when compared to the $\mathrm{HT}$ in this program. This difference came about as the emissions of the CAT and Cummins MEs differ at low power levels where the engines mainly operate and which are only weakly considered in the Tier 2 determination. Again most reductions and benefits occurred in the transit mode, mainly due to the energy management system rather than the batteries.

\subsubsection{Scenario 2}

Conventional tugs typically have $\mathrm{AE}$ with power rating at the lower level of the JD 6081 in this work as compared with the Cummins QSK-11 M. Therefore, an interesting scenario might be a CT powered by CAT $3512 \mathrm{C}$ main engines and the JD 6081 auxiliaries and a HT powered by CAT 3512C MEs with Cummins QSK11-M AEs. The reductions or benefits of the HT of scenario 2 were similar to that of retrofit scenario 1 (Table 4).

\section{Implications}

It is essential that the real world activity and emissions be measured for determining an accurate inventory, rather than accept certification values. In this study using certification values instead of measured values would result in overestimation of emissions by about $65 \%$. With measured activity and emissions, this study shows that a hybrid tug has reduced $\mathrm{CO}_{2}$ (greenhouse gas), $\mathrm{NO}_{\mathrm{x}}$, and $\mathrm{PM}_{2.5}$ by 27,51 and $73 \%$, respectively, when compared with a conventional tug. Assuming similar results when replacing conventional with hybrid tugs in the San Pedro Bay, then the benefits in tons per year are the following: 11,879 for $\mathrm{CO}_{2}, 374$ for $\mathrm{NO}_{\mathrm{x}}$, and 19 for $\mathrm{PM}_{2.5}$. This is equivalent to $\mathrm{NO}_{\mathrm{x}}$ emissions from 434 class 8 trucks driving 100,000 miles per year.

Table 4 Overall reductions for retrofit scenarios 1 and 2

\begin{tabular}{llllll}
\hline $\mathrm{PM}_{2.5}(\mathrm{~g} / \mathrm{h})$ & \multicolumn{2}{c}{$\mathrm{NO}_{\mathrm{x}}(\mathrm{g} / \mathrm{h})$} & \multicolumn{2}{l}{$\mathrm{CO}_{2}(\mathrm{~kg} / \mathrm{h})$} \\
\hline Scenario 1 & Scenario 2 & Scenario 1 & Scenario 2 & Scenario 1 & Scenario 2 \\
$57 \%$ & $60 \%$ & $38 \%$ & $36 \%$ & $31 \%$ & $30 \%$ \\
\hline
\end{tabular}




\section{Conclusions}

This study developed a test protocol to quantify the emissions from any hybrid off-road mobile sources. Test protocol was implemented on world's first hybrid tug and emission benefits were determined by comparing against a conventional tug boat. A month-long continuous logging of all power sources from both vessels revealed that the tugs operated in five different modes - dock, standby, transit, ship assist, and barge move. The average weighting factors for these modes were found to be $0.54,0.07,0.17,0.17$, and 0.05 , respectively. The developed in-use duty cycles based on activity data were found to be well below the load factors specified in the standard ISO duty cycles. Depending upon the application, same engine can have different in-use duty cycle. Therefore, in-use duty cycles must be developed to quantify emissions and subsequently reduce the uncertainties in the emission inventories. The diesel-electric drive train on the hybrid tug that allowed the use of auxiliary power for propulsion was the primary cause for the overall inuse emission reductions as opposed to the batteries. The overall reductions with the hybrid technology were found to be $73 \%$ for $\mathrm{PM}_{2.5}, 51 \%$ for $\mathrm{NO}_{\mathrm{x}}$, and $27 \%$ for $\mathrm{CO}_{2}$. The transit operating mode was the most significant contributor to the overall emission reductions in this off-road application. In this mode, the hybrid was powered by one or two auxiliary engines and batteries while the conventional tug used one auxiliary and two main engines. The reductions in the fuel equivalent $\mathrm{CO}_{2}$ emissions were in good agreement with the fuel savings measured by the tugboat owner over an 8 month period suggesting robust test protocol and analysis techniques.

Acknowledgments The authors thank CARB for their financial support and the technical working group (members from CARB, Foss Maritime Company, Pacific Merchant Shipping Association, Ports of Los Angeles and Long Beach, South Coast Air Quality Management District, and the U.S. Environmental Protection Agency) for overseeing the progress of the project. Edward Sun and Wayne McMahon of CARB for their input on HEV testing; Foss Maritime Company, Aspin Kemp and Associates and Startcrest Consulting LLC for their for their generous help onboard the vessels; Charles Bufalino, Kurt Bumiller, Mac MacClanahan, and Ed Sponsler for their efforts in the test preparation; Kathalena Cocker, Poornima Dixit, James Theodore Gutierrez, Sindhuja Ranganathan, Letia Solomon, David Torres, and Charles Wardle for their support in preparation and analysis of the sample media; Alex Vu for his help in developing Python 2.6 codes for data analysis; Kyle Loggins for plotting the schematic of the hybrid drive train.

Supporting Information Available Schematic of the hybrid tug's diesel-electric drive train, details of data logging and emission testing procedure, calculating operating mode weighting factors, developing engine histograms, determining engine loads and exhaust flow rates, load correction for main engine on the conventional tug, calculating modal, and overall weighted average emission factors, engine specifications, select fuel properties, weekly variation in operating mode weighting factors, engine histograms for hybrid tug without batteries, average load requirements for each operating mode, emission factors from emissions testing phase $1, \mathrm{PM}_{2.5}$ mass balances for all four test engines, comparison of the emission factors from emission testing phases 1 and 2, power plant emissions factors used for shore power calculations, and the modal and overall in-use emissions for the conventional tug, hybrid tug with, and without batteries are all provided in the Supporting Information.

\section{References}

1. Sawyer, R.F.: Vehicle emissions: progress and challenges. J Expo Sci Environ Epidemiol 20, 487-488 (2010)

2. California Air Resources Board. California Exhaust Emission Standards and Test Procedures for 2009 and Subsequent Model Zero-Emission Vehicles, and Hybrid Electric Vehicles, In the Passenger Car, Light-Duty Truck and Medium-Duty Vehicle Classes 2009. http://www.imo.org/ Safety/mainframe.asp?topic_id $=1709 \&$ doc_id $=9123$

3. SAE International. Recommended Practice for Measuring the Exhaust Emissions and Fuel Economy of Hybrid Electric Vehicles, Including Plug-in Hybrid Vehicles. Society of Automotive Engineers 2010, J1711_201006, 2010-0-08

4. SAE International. Recommended Practice for Measuring Fuel Economy and Emissions of Hybrid-Electric and Conventional Heavy-Duty Vehicles. Society of Automotive Engineers 2010, J2711, 2010-12-10.

5. Silva, C., Ross, M., Farias, T.: Evaluation of energy consumption, emissions and cost of plug-in hybrid vehicles. Energy Convers Manage 50(7), 1635-1643 (2009)

6. Taymaz, I., Benli, M.: Emission and fuel economy for a hybrid Vehicle. Fuel 115, 812-817 (2014)

7. Nüesch, T., Wang, M., Isenegger, P., Onder, C.H., Rüdiger, S., Macri Lassus, P., Guzzella, L.: Optimal energy management for a diesel hybrid electric vehicle considering transient $\mathrm{PM}$ and quasi-static $\mathrm{NO}_{\mathrm{X}}$ emissions. Control Eng Pract 29, 266-276 (2014)

8. Davies, J., Kurani, K.S.: Moving from assumption to observation: implications for energy and emissions impacts of plug-in hybrid electric vehicles. Energy Policy 62, 550-560 (2013)

9. An, F.; Barth, M., Critical Issues in Quantifying Hybrid Electric Vehicle Emissions and Fuel Consumption. SAE Technical Paper 981902, 1998, doi:10.4271/981902

10. Fontaras, G., Pistikopoulos, P., Samara, Z.: Experimental evaluations of hybrid vehicle fuel economy and pollutant emissions over real-world simulation driving. Atmos Environ 42(18), 4023-4035 (2008)

11. Takada, Y.; Ueki, S.; Saito, A., Investigation into Fuel Economy and $\mathrm{NO}_{\mathrm{X}}$ Emissions of Light Duty Hybrid Truck in Real Traffic Conditions. Society of Automotive Engineers 2005, SAE Technical paper 2005-01-0265. doi:10.4271/ 2005-01-0265

12. Takada, Y.; Ueki, S.; Saito, A., Study on fuel economy and $\mathrm{NO}_{\mathrm{X}}$ emissions of medium duty hybrid truck in real traffic conditions. Society of Automotive Engineers 2004, Appl Energy 2004-01-1086. doi:10.4271/2004-01-1086.

13. Zhang, S., Wu, Y., Hu, J., Huang, R., Zhou, Y., Bao, X., Fu, L., Hao, J.: Can euro $\mathrm{V}$ heavy-duty diesel engines, diesel hybrid and alternative fuel technologies mitigate $\mathrm{NO}_{\mathrm{X}}$ emissions? New evidence from on-road test for buses in china. Appl Energy 132, 118-126 (2014) 